\title{
The Listening Comprehension Strategies Used by College Students to Cope with the Aural Problems in EFL Classes: An Analytical Study
}

\author{
Nahed Mohamed Mahmoud Ghoneim ${ }^{1}$ \\ ${ }^{1}$ Menoufia University, Egypt \\ Correspondence: Nahed Mohamed Mahmoud Ghoneim, Lecturer of Teaching English as a Foreign Language, \\ Department of Curriculum and Teaching Methods, Faculty of Education, Menoufia University, Egypt. Tel: \\ 201-068-364-621. E-mail: amomoon@yahoo.com
}

\author{
Received: November 1, 2012 Accepted: December 24, 2012 Online Published: January 9, 2013 \\ doi:10.5539/elt.v6n2p100 URL: http://dx.doi.org/10.5539/elt.v6n2p100
}

\begin{abstract}
The current study focused on the problems which students encounter while listening to the English language, the mental processes they activate in listening comprehension, and the strategies they use in different phases of comprehension. Also, it aimed to find out whether there were any differences between advanced and intermediate students in their use of the listening strategies. Data was collected using the "think aloud" technique in which students ( $4^{\text {th }}$ year English majors, Faculty of Education, Menoufia University) were asked to mention any problem they face during a listening comprehension activity and indicate what they were thinking to solve the problem. The findings indicated that advanced and intermediate participants encountered the same problems with different percentages, and activated three groups of processes. The advanced group students used top down strategies more than the intermediate ones.
\end{abstract}

Keywords: listening comprehension strategies, aural problems, think aloud, intellectual processes

\section{Introduction}

Listening in English is an active skill requiring listeners to deal with a variety of complicated tasks, such as discriminating between sounds and interpreting stress and intonation. Listeners use a variety of mental processes to give meaning to the information they listen to. These mental steps can be broadly described as listening comprehension strategies. As indicated by Song (2008), listeners often do not handle listening tasks in an effective way utilizing these strategies successfully. They are not aware of listening strategies. Chamot (2005) pointed out that less successful language learners do not have the knowledge needed to select appropriate strategies. Goh (2000) emphasized the importance of these strategies by arguing that learners' awareness is related to effective learning in all learning contexts. Taguchi (2005) drew attention to the specific context of L2 listening and claim that strategies have a direct and positive influence on listening performance. Osada (2004), and Sharma (2007) also indicated that one of the distinctive features differentiating successful listeners from unsuccessful ones is their use of listening comprehension strategies and they supported the idea that analyzing the role of these strategies in L2 listening helps listeners to approach the listening task more effectively.

\subsection{Background and Problem of the Study}

Many researchers (Corder (1982), Ellis (1986), Song (2008), Chamot (2005), and Goh (2000), assured that more studies are needed to increase learners' awareness of strategies used in listening. As reception processes and strategies of the spoken language are a relatively unexplored field of study, the focus of this study is to analyze the mental steps involved in the reception strategies of listening.

The researcher conducted a pilot study where she asked (50) students in the fourth year of the English department to listen to a passage and then answer some questions based on their comprehension of the listening passage. Findings indicated that most students encountered problems in understanding the listening passage. After that, the researcher interviewed the students and asked them about the reason for committing mistakes after listening to the passage. They said that the listening skill is the most difficult of all the language skill because they do not receive training to develop their listening skill.

\subsection{Aim of the Study}

This study aimed to investigate the listening comprehension strategies which students in the fourth year of the 
English department used when an aural message is processed.

\subsection{Questions of the Study}

The current study tried to find answers to the following questions:

1-What problems do advanced and intermediate learners of English as a foreign language experience in listening comprehension?

2-What planning processes do advanced and intermediate learners activate in listening comprehension?

3-What are the strategies which advanced and intermediate learners select to solve the problems experienced in listening comprehension?

4-To what extent do advanced and intermediate learners differ in their use of the listening comprehension strategies?

\subsection{Significance of the Study}

The study is significant as it might help:

Students, as strategic knowledge is part of what must be learned in order to solve problems in listening. If students learn the strategies by themselves through discovery methods, they will acquire a more active approach to problem solving that may be generalized to other kinds of listening tasks.

Teachers, as adding knowledge to the processes leading to listening comprehension in the foreign language could help teachers to examine what listening entails. After the exploration of the process, teachers can guide learners in the use of alternative strategies for listening. As a result, these processes and strategies may provide insights for teachers to employ in designing the listening components of their programs. On the other hand, developing taxonomy of the strategies used by proficient listeners could help the teachers use these strategies to improve the listening habits of poor listeners.

\subsection{Delimitations of the Study}

1. The present study was concerned with analyzing the listening comprehension strategies.

2. The sample of the study consisted of (40) students in the fourth year of the English Department in the Faculty of Education, Menoufia University.

\subsection{Definition of Terms}

\subsubsection{Listening Comprehension Strategies}

The researcher adopted Vandergrift's (2007) definition. The term is used to refer to the strategies that listeners consciously or unconsciously use in order to understand, analyze, and interpret a text. The use of these strategies can make authentic texts more accessible in the early stages of learning a language, so that the process becomes more relevant and interesting to the learners. Useful listening strategies are developed when teachers provide students with abundant opportunities to practice listening outside the evaluation conditions.

\subsubsection{Aural Problems}

The term is operationally defined as the difficulties which students in the fourth year of the English Department, Faculty of Education, Menoufia University suffer from as a result of their inability to make use of listening comprehension strategies.

\section{Review of Literature}

The purpose of this review is twofold; first, to clarify the nature and the importance of the listening comprehension strategies; second, to illustrate the approach that can be used to determine the processes and the strategies which EFL learners use to solve their listening problems.

Rivers (1981) pointed out the importance of developing listening skills citing research studies that show that adults spend $40 \%$ to $50 \%$ of their time listening, $25-30 \%$ speaking, $11-16 \%$ reading, and only about $9 \%$ writing. When almost half of the communicative interaction involves aural comprehension skills, it seems that the development of these skills should be studied more closely and systematically.

The listening skill has not been fully investigated in the field of foreign language acquisition mainly because listening processes are difficult to explore. The listening process is so hard to describe because it is a covert activity (Chamot 2005). It is easy to cover up the mistakes of comprehension. Smiling or nodding could mislead the teacher and wrongly make him/her believe that his students are following him. In situations where accurate comprehension is needed, teachers discover that listening is an active skill. As Sadighi \& Zare (2006) pointed out, 
the difficulty of exploring the listening skill and the assumption that learners develop the listening skill naturally have resulted in a lack of research in the field of the listening skill of the foreign language. Researchers and teachers do not know much about the nature of the process of foreign language listening comprehension.

\subsection{Problems of Listening}

Underwood (1989) Doff \& Christopher (2004), Piolat, (2008), and Sharma (2006) outlined potential problems that could hinder listening Comprehension: First, the speed of delivery is beyond the control of listeners. Second, it is not always possible for learners to have words repeated. This is a main problem in learning situations. Third, the small size of the learner vocabulary frequently impedes listening comprehension. The speaker does not always use words the listener knows. Sometimes when listeners encounter a new word, they stop to figure out the meaning of that word, and they therefore, miss the next part of the speech.

Fourth, listeners may not recognize the signals that the speaker is using to move from one point to another especially if the learner is listening to a radio where he can not see the facial expressions of the speaker. Fifth, it can be very challenging for listeners to concentrate in a foreign language. It is generally known that in listening, even a slight break or a wander in attention can impede comprehension. When the topic of the listening passage is interesting, it can be easier for listeners to concentrate and follow the passage; however, students sometimes feel that listening is very challenging even when they are interested in the topic because it requires a lot of effort to figure out the meaning intended by the speaker. Sixth, the learning habits which teachers emphasize in the classroom such as the desire to understand the meaning of every word could impede the use of top down strategies in listening. Teachers want students to understand every word they encounter while listening by pronouncing and repeating words clearly and carefully, and by speaking slowly and so forth. As a result, students tend to feel worried when they fail to recognize what a particular word means. Seventh and last, comprehension problems arise when students lack contextual knowledge. Even if students can understand the main idea of the text, they may still find it difficult to comprehend the whole meaning of the text. In order to overcome these listening comprehension problems, learners need to develop techniques known as "listening strategies".

According to Freeman (2004) and Lin (2006), listening comprehension strategies are techniques or activities that contribute directly to the comprehension and recall of listening input. Listening strategies can be classified by how the listener processes the input. Top-down strategies are listener based; the listener taps into background knowledge of the topic, the situation or context, the type of text, and the language. This background knowledge activates a set of expectations that help the listener to interpret what is heard and anticipate what will come next.

Bottom-up strategies are text based; the listener relies on the language in the message, that is, the combination of sounds, words, and grammar that creates meaning. Listeners also use metacognitive strategies to plan, monitor, and evaluate their listening. Listening strategies refer to decision making operations which a learner employs in processing a listening task. These strategies are determined in part by specific task requirements, by problem content, by situational constraints, and by prior knowledge and experience which the listener possesses and brings to bear in each task. (Sakai 2009).

As Faerch and Kasper (1980) pointed out, the development of cognitive theories has moved research from linear analysis of linguistic products, to a psycholinguistic study of the underlying processes. However, very little data exist to enlighten researchers and teachers about the cognitive processes involved in foreign language listening. The listening skill of the foreign language has recently begun to be studied through experimentation.

\subsection{Approaches to Listening}

A review of the literature on listening reveals a significant divergence, in views about the process, that is rooted in different theoretical assumptions of how to derive meaning from a string of language signs and of those elements that are considered crucial for achieving comprehension. These approaches can be grouped in three categories:

1- A linguistic approach: it aims to determine how the listener arrives at a structural description of the utterances based on the phonological, lexical, syntactic, and semantic aspects of language.

2- A communicative approach: it sees comprehension primarily as the result of an interaction between speaker and listener. Comprehension is achieved when the listener has successfully identified what the speaker intended to communicate with his utterances (Vandergrift \& Tafaghodtari, 2010).

3- A psycholinguistic approach: it tries to identify and classify the mental steps and cognitive strategies used by the listener. These strategies are taxonomized from a process-oriented perspective, that is, by taking into account the processes underlying their use rather than their product or linguistic outcome.

The psycholinguistic definition offered by Faerch and Kasper (1980:60) describes communication strategies as 
"potentially conscious plans for solving what to an individual presents itself as a problem in reaching a particular goal". This definition relates to problems experienced by the learner in speech reception. Communication strategies are the product of cooperation between two speakers. This implies that both the problem and its solution must somewhat surface in the performance. Corder (1982), and Ellis (1986) in their discussions of strategies of communication, believe that there is lack of research and knowledge in the area of 'receptive strategies. Research is mainly concerned with the production processes because the researcher needs the support of the learner's actual utterances to guide his research results.

Long \& Ross (2009) stated that of the four skills, listening is perhaps the most difficult for learners. In normal situations of communication, the listener can ask the speaker to reiterate or to clarify what was said, but this is not the case when the listener has no control over the rate and manner of delivery as for example when listening to a radio broadcast. Because of these limitations, the investigation of the mental operations involved in listening has been difficult and challenging for research. Faerch et al. (1984) believe that the ability to understand the spoken word has traditionally been considered a passive decoding skill. However, recent psycholinguistic and neuro-linguistic research in speech reception and comprehension has provided empirical evidence that listening is a complex operation which consists of active processes and strategies. In fact, in extracting meaning from spoken discourse, the listener goes through several mental steps and engages in specific cognitive strategies

\subsection{Think Aloud Technique}

Think aloud technique reactivates traces of cognitive processes. Ericsson and Simon (1984) suggest that it allows the previously heeded information still available in the memory to be reported; this in turn facilitates retrieval of information stored. Ericsson and Simon suggest that in order to minimize problems related to retrieval from long term memory, researchers should study cognitive processes of short duration where the verbal responses lag the task processes by only a brief interval.

Faerch and Kasper (1987) indicate that it is crucial to familiarize informants to verbal reports while attending to a task. Therefore, Faerch and Kasper recommend a practice phase before the data collection. During the training, the subjects are exposed to recorded demonstrations of think aloud protocols and are asked to practice this procedure on a similar task. Also, Ericsson and Simon (1987) recommend giving initial instruction to subjects, setting warm - up procedures, and developing ways to remind subjects about the verbal report instruction before starting an experimental study in order to make sure that all subjects use the same verbal report procedure. The researcher should also be present during the experiment to monitor the verbalizations.

Until recently, research on processes and strategies has tended to deal with listening in interactive contexts or written tests. In this way, only comprehension is tested rather than the mental steps that lead to comprehension. Faerch (1984) pointed out that a research method using "think aloud" is thus the most suitable in gathering information about the listening cognitive processes and strategies. Using this method helps to investigate how listeners solve receptive problems not by relying on methods based on production, but by trying to design procedures that can shed light on listeners' receptive techniques. These processes and strategies cannot be identified in any precise way from observable performance data.

Ericsson and Simon (1987) warn that as particular processes become highly practiced, they become more and more fully automated. Automation means that intermediate steps are carried out without being interpreted. Because of this tendency over time for recurrent cognitive processes to become automated, the subjects of this study were exposed to a listening task that includes different points that could be problematic, thus bringing into operation controlled processes, which would be available for immediate retrospection. It is evident that matching the level of the stimulus to the comprehension level of the subjects is vital. If the stimulus is too complex, it is perceived as noise. On the other hand, a stimulus that is too simple is comprehended immediately, inducing only automated mental steps instead of controlled ones, and revealing little about listening processes.

\subsection{Previous Studies Related to FL Listening Strategies}

Attia (2002) conducted a study to investigate the effect of a strategy-based instruction program on developing EFL listening comprehension skills. The main purpose of this study was to probe empirically the effects of three different approaches: strategy training, metacognitive instruction and pure exposure, on listening performance, attitudes, self-efficacy and on strategy knowledge, use and perceived value among student teachers of English in Egypt. Moreover, the interaction between these three treatments and students' proficiency levels (high/low) was an item of interest. The results of the study demonstrated that strategy training is better in promoting all the variables addressed and compares favorably with metacognitive instruction and pure exposure. Results also showed that the strategy training approach holds great potential for developing students' independence and that it 
moved them towards autonomy. Furthermore, the findings indicated that the metacognitive instruction group performed significantly better than the control group only in listening and attitudes.

Amin, Amin, \& Aly (2011) conducted a study entitled "A Correlation Study between EFL Strategic Listening and Listening Comprehension Skills among Secondary School Students". Eighty secondary school students participated in this study. Participants' strategic listening was measured by a Strategic Listening Interview (SLI), a Strategic Listening Questionnaire (SLQ) and a Strategic Listening Checklist (SLC) with think-aloud protocol. Their listening comprehension skills were measured by an EFL listening comprehension test. A Pearson correlation analysis was run to test the correlation between strategic listening and listening comprehension test scores. The findings revealed that the relationship between strategic listening and listening comprehension was positive and significant. The higher the level of strategic listening these students obtained, the higher the score they attained on the listening comprehension test and vice versa.

Carissa (1997) investigated the possible existence of a sequence of use of listening comprehension strategies by advanced ESL learners. Although the results revealed that these students had a similar pattern of strategy use regardless of their gender and English achievement, those students with higher ability in listening comprehension tended to use the following six strategies more often than the other students: self-evaluation, summarization, elaboration, inference, feedback, and reprise. Murphy (1985, as reported in Carissa 1997) worked with 12 intermediate university students and concluded that the high achievers used their prior knowledge, made guesses (inferring), and monitored their comprehension more often than did low achievers.

Kasper (1984) has conducted an exploratory study on reception in aural communication focusing on FL learners' comprehension of speech act and discourse functions, referred to as 'pragmatic comprehension, in role-play situations of learner-native speaker discourse. The situations were between German learners of English and native speakers. This study looked into the types of learners' pragmatic misunderstanding; that is their failure to understand the native speaker's communicative intention. The data analysis indicated that the learners relied too heavily on bottom-up processing. This study explored the aspect of pragmatic comprehension in aural communication, however, it did not address the question about listeners' specific comprehension problems or how they solved such problems.

The first attempt to investigate empirically the notion of listening comprehension was that of DeFilippis' (1980) with a study that analyzed and compared the listening strategies of skillful and unskillful L2 learners in French. On the basis of raw test scores on the MLA Cooperative Foreign Language Test in French, DeFilippis identified the top thirteen students as skillful listeners, and the bottom thirteen students as unskillful listeners. DeFilippis elicited the listening strategies of research participants by using a test instrument consisting of a series of audio-taped aural comprehension tasks at five developmental levels. This test was administered to each subject within the parameters of a semi-structured interview. The findings indicated that while skillful listeners answered more questions correctly and requested fewer playbacks of the aural comprehension tasks, the listening strategies of both groups were similar.

Another study in the processes and strategies of listening was conducted by Martin (1982). This investigation was a case study and was developed in three stages with five ESL native Spanish speaking consultants participating in nine 50-minute interviews. Much of the data was collected in interviews which consisted of immediate retrospective think aloud reporting. The listening strategies described by the consultants were categorized into two groups: 21 on the word level and 13 on the idea level. While the former were used to associate meaning with specific words, the latter dealt with the establishment of a topic and the association of subsequent meanings to the main idea.

\section{Method and Procedures}

\subsection{Method of Use}

In order to reach a reliable identification of participants' listening processes and strategies, the current study used the "Think Aloud" technique. Forty sessions were undertaken; one session for each participant

\subsection{Participants}

The present study was conducted on two groups; 20 advanced learners of English as a foreign language and 20 intermediate ones. The participants were students in the fourth year of the English department in the Faculty of Education. The participants were selected on the basis of their listening proficiency level. A test was administered to the participants to divide them to advanced and intermediate. 


\subsection{Instruments}

\subsubsection{A Listening Comprehension Test (Appendix 1.)}

\subsubsection{Test Description}

The test consisted of 16 multiple choice questions based on two listening passages; 8 MCQs on each. Based on the results of the test, participants were divided into advanced and intermediate. The current study adopted DeFilippis's (1980) method of dividing skilful and unskillful learners. The advanced participants were the top twenty students whereas the intermediate participants were the bottom twenty ones.

\subsubsection{Test Validity}

The listening comprehension test was given to a panel of jury in the field of teaching English as a foreign language to judge its validity. Two questions were replaced by others because of their ambiguity.

\subsubsection{Test Reliability}

The split-half method was used to determine the reliability of the test. The correlation coefficient was $78 \%$ which is highly reliable.

\section{Procedures of Data Collection}

\subsection{Selecting and Pre-testing of the Listening Material}

In order to reinforce the reliability of this study, an orientation session was undertaken prior to conducting the actual investigation. It gave the opportunity to pretest and select the listening comprehension task. It aimed to determine its appropriateness to subjects; to revise and clearly write the directions in the script so that the participants understood what was expected of them and could accurately report their listening processes and strategies; to conduct several practice sessions under the conditions comparable to those anticipated in the actual study and to analyze the verbal reports of participants in order to determine a method of data analysis.

As a result of the session, a criterion for the selection of the listening task was developed. The listening task was selected, considering the length, with a total listening time of 8 minutes. The clarity of voices, pronunciation and accent of the speakers, and a moderate interference of background sounds or noises were also considered. As a result of the pre-testing and selecting, the listening task used in the orientation session was replaced with a clearer and longer one. The listening material was a conversation between two persons. The conversation included words with different meanings, numbers, names of places and persons. Before the beginning of the experiment, participants were given some instructions and practice in verbalizing their thoughts immediately after attending to some parts of the listening tasks. Think aloud reports were conducted in English. The verbalizations produced were fully transcribed for each participant.

\subsection{Setting}

In order to standardize the conditions under which the listening task was administered, the participants were given the same directions for responding. All sessions were held in the same setting using the same equipment and under the same set of conditions. One tape recorder was used to play the recordings of the listening task. In order to familiarize participants with the use of recording equipment and think aloud procedure, the researcher gave a training session. As suggested by Faerch and Kasper (1987), Ericsson and Simon (1984, 1987), the researcher clarified what type of information processing was required to generate the prescribed immediate retrospective verbalization and "what role the internal activation of oral information has" (Ericsson \& Simon, 1984:66). Once the researcher ascertained that the participants were familiar with the verbalization technique and able to describe their processes and strategies, the study proceeded. The researcher was always present during the experiment to monitor the verbalizations and to ask the participants to explain what they meant by something, or to ask them to explain their solution processes.

\subsection{Procedures for Eliciting Think Aloud Data}

Each participant was asked to listen to the listening task, to stop the recording any time he/she wants, to briefly explain what is understood and to verbalize the thoughts running in his/her mind while listening. By letting the participants take intermittent breaks during the listening task and by self-selecting the moments when their oral responses were ready to be expressed, the researcher was able to record these responses while the participants' thoughts were still in the process of formation. The adaptation of this procedure in the current study permitted the exploration of listening processes in action. During each meeting, the researcher showed no sign of approval or disapproval and remained neutral while participants produced their verbal reports.

At the beginning of each session (including the orientation sessions) participants were given the following 
directions: You are going to listen to an 8 minute English conversation. Please, listen to the recording, interrupt the tape as often as you wish, immediately after each interruption, verbalize the thoughts that were running in your mind as you are listening and tell me what goes through in your mind as you listen to the conversation Reconstruct any comprehension problem you experience, explain how you plan to solve the problem and describe the strategies you select to reach.

After the verbal protocols were transcribed, the problems, planning processes, and strategies reported by the participants were identified and arranged into a framework. The verbal protocols were coded according to a preliminary list of listening processes and strategies which resulted from piloting the test and which were refined during the actual study. The analysis of the qualitative data produced taxonomy of specific listening problems, planning processes, and corresponding strategies. To test the reliability of the coding scheme, the researcher and another teacher, who was specially trained by the researcher, coded the verbal protocols. The degree of agreement between the teacher and the researcher was estimated $85 \%$. Any discrepancies remaining in coding were resolved through discussion.

\section{Data Processing and Analysis}

After all the data of the actual study had been collected, there were forty separate protocols, one for each participant. Then, the coding procedures for the Think aloud Protocols were analyzed by using Faerch and Kasper's (1983) model of intellectual behavior in determining problem — solving processes and strategies. In this model of intellectual behavior, the first stage involves the identification of a specific comprehension problem and the reason that caused the problem (a word, an idea, etc.); the second stage represents the formulation of a hypothesis about a solution path. In other words, the processes which were activated to select a certain strategy, the third stage is the product of the preceding mental activity, the operation selected to solve the problem. The fourth stage represents the solution to the problem.

\section{Discussion and Interpretation}

After analyzing the data, it appeared that the listening problems, processes and strategies were categorized into three taxonomies. Participants encountered six problems, activated three groups of processes, and selected eleven strategies to solve the listening problems.

Out of the participants' responses, it has been found that $80 \%$ of the advanced learners used top-down strategies (e.g. making inferences to get the meaning of the unknown word) more than bottom up strategies. Sixty five percent $(65 \%)$ of the intermediate learners emphasized the use of bottom up strategies (e.g. focusing on the meaning of every word to understand the text). Table 1 shows the problems which advanced participants encountered while listening, the processes activated and the strategies used to solve the problems.

Table 1. Listening Strategies Used by the Advanced Participants to solve their Aural Problems

\begin{tabular}{|c|c|c|c|}
\hline Participants & Problem & Process & Strategy \\
\hline $1,10,16,19$ & $\begin{array}{l}\text { Hearing an } \\
\text { unknown word }\end{array}$ & Linguistic process & $\begin{array}{l}\text { Recalling similar sounds } \\
\text { Background knowledge }\end{array}$ \\
\hline $2,4,8,9$ & $\begin{array}{l}\text { Hearing an } \\
\text { unknown word }\end{array}$ & Connecting process & Associating/Context clues \\
\hline $3,7,11,14$ & $\begin{array}{l}\text { Hearing an } \\
\text { unknown word }\end{array}$ & Linguistic process & $\begin{array}{l}\text { Vocalization/Visualization } \\
\text { Word by word meaning }\end{array}$ \\
\hline $2,5,6,12,4,8,17$ & $\begin{array}{l}\text { Known words with } \\
\text { no connection to } \\
\text { the topic }\end{array}$ & Connecting process & $\begin{array}{l}\text { Associating, } \\
\text { Making prediction } \\
\text { Seeking confirmation, } \\
\text { Rejecting wrong hypotheses }\end{array}$ \\
\hline $1,6,9,11,13,15,18,20$ & $\begin{array}{l}\text { Words with } \\
\text { multiple meanings }\end{array}$ & $\begin{array}{l}\text { Comprehension- } \\
\text { gathering } \\
\text { Connecting process }\end{array}$ & $\begin{array}{l}\text { Recognizing stress, } \\
\text { Making inferences, } \\
\text { Using Background } \\
\text { knowledge }\end{array}$ \\
\hline $3,6,8,11,20$ & $\begin{array}{l}\text { Inability to } \\
\text { recognize proper } \\
\text { Names and } \\
\text { places }\end{array}$ & $\begin{array}{l}\text { Linguistic process } \\
\text { Connecting process }\end{array}$ & $\begin{array}{l}\text { Context clues } \\
\text { Associating, } \\
\text { Background knowledge }\end{array}$ \\
\hline $1,7,12$, & $\begin{array}{ll}\text { Hearing } & \text { words } \\
\text { incorrectly }\end{array}$ & $\begin{array}{l}\text { Comprehension- } \\
\text { gathering }\end{array}$ & $\begin{array}{l}\text { Seeking Confirmation, } \\
\text { Rejecting wrong hypotheses, }\end{array}$ \\
\hline $6,13,14,18$ & $\begin{array}{l}\text { Inability } \\
\text { understand } \\
\text { numbers }\end{array}$ & $\begin{array}{l}\text { Linguistic process } \\
\text { Connecting process }\end{array}$ & $\begin{array}{l}\text { Context clues } \\
\text { Background knowledge } \\
\text { Selecting }\end{array}$ \\
\hline
\end{tabular}


Table 1 shows that participants experienced different problems while listening to the conversation. They activated certain processes to select the strategies that could help them solve these problems. The three groups of processes activated by the subjects are:

1. Comprehension-gathering processes: they lead to strategies that try to get the meaning of the text such as "making inferences" and "using background knowledge"

2. Linguistic processes: they lead to the selection of strategies that help to understand specific linguistic items such as "Context clues" and "visualization"

3. Connecting processes: they activate the choice of strategies that try to establish relationships between word meanings and the main topic such as "Associating". As for the strategies used, the following is a survey of them:

1. As for the problem "Hearing an unknown word", some participants said that they heard new words and realized that they did not know the meaning of these words. They activated the linguistic and connecting processes in order to help them select strategies such as context clues and associating to recognize the meaning of the words. Other participants said that they could infer the meanings from the context. The second participant said that he tried to get the meaning of the new words out of his understanding of the whole text, but he could not. The first, tenth, sixteenth, and nineteenth used the strategy of "recalling similar sounds". They said that they repeated phonetically similar combinations of sounds in an attempt to match the input to the new word they heard. They also tried to visualize the spelling of another new word in order to help them recognize its meaning. The seventh participant said that he could make an association between the new word and another known word. This helped him predict the meaning of the new word.

2. The third, eighth, and twentieth participants could not recognize the proper names mentioned in the conversation. They activated connecting and linguistic processes to select the strategies of using background knowledge, context clues and associating. The sixth participant said that the word he heard is familiar to him. He heard it before. He believes that it is a place name. The third and eighth participants said that they could infer from the whole text that the word they heard is a name of a place. The eleventh participant said that when he heard the sentence that follows the place name, he could make an association between them and understood that it is a name of a place.

3. The first, the seventh and the twelfth participants did not hear words correctly, and therefore, they translated them in a wrong way. They activated the process of comprehension gathering to select the strategy of seeking confirmation of the meaning of these words. They said that nothing in the conversation could help them confirm the meaning of these words. At last, they reject them and said that they can not recognize these words.

4. The sixth, thirteenth, fourteenth and eighteenth participants have difficulty in understanding numbers. They activated connecting and linguistic processes to use the strategies of "context clues", "using background knowledge" and "selecting". The sixth participant said that out of his previous knowledge, he believes that the number he heard is a street number. The fourteenth participant said that he heard a number but he could not recognize it. He selected to move on. The thirteenth and eighteenth participants said that they could infer from the context that it is a street number.

5. Eight participants experienced the problem "words with multiple meanings". They activated the connecting and comprehension-gathering processes to select the strategies of Recognizing stress to get meaning, making inferences, Using Background knowledge and associating. They infer from the context the most appropriate meaning.

6. Seven participants said that they heard familiar words but they could not make a connection between these words and the text. They activated the connecting processes to select the strategies of "associating", "making prediction" and "seeking confirmation". Three participants said that they tried to associate between this word and the text in order to realize how the word is related to the text. They could predict the meaning. Four participants said that they tried to seek confirmation of the meaning they know. At last, they could realize the connection between the word and the text. 
Table 2. Listening Strategies Used by the Intermediate Participants to solve their Aural Problems

\begin{tabular}{|c|c|c|c|}
\hline Participants & Problem & Process & Strategy \\
\hline 1 to $10,13,14,17,18,19$ & $\begin{array}{l}\text { Hearing an } \\
\text { unknown word }\end{array}$ & Linguistic process & $\begin{array}{l}\text { Recalling similar sounds } \\
\text { Background Knowledge } \\
\text { Word by Word meaning }\end{array}$ \\
\hline 1 to 13 & $\begin{array}{l}\text { Known words with } \\
\text { no connection To } \\
\text { the topic }\end{array}$ & Connecting process & $\begin{array}{l}\text { Associating, } \\
\text { Selecting to move on } \\
\text { Seeking confirmation, } \\
\text { Rejecting wrong hypotheses }\end{array}$ \\
\hline 1 to $9,14,17,18$ & $\begin{array}{l}\text { Words with } \\
\text { multiple meanings }\end{array}$ & $\begin{array}{l}\text { Comprehension- } \\
\text { gathering }\end{array}$ & $\begin{array}{l}\text { Recognizing stress } \\
\text { Word by Word meaning, } \\
\text { Background Knowledge }\end{array}$ \\
\hline $4,6,7,8,9,11,12,15,16,20$ & $\begin{array}{l}\text { Inability to } \\
\text { recognize proper } \\
\text { Names and } \\
\text { places }\end{array}$ & $\begin{array}{l}\text { Connecting process } \\
\text { Linguistic process }\end{array}$ & $\begin{array}{l}\text { Context clues } \\
\text { Associating, } \\
\text { Word by Word meaning } \\
\text { Making predictions }\end{array}$ \\
\hline $4,7,8,10,11,13,15$ & $\begin{array}{ll}\text { Hearing } & \text { words } \\
\text { incorrectly } & \end{array}$ & Linguistic process & $\begin{array}{l}\text { Word by Word meaning } \\
\text { Vocalization/Visualization } \\
\text { Selecting to move on } \\
\text { Making Inferences }\end{array}$ \\
\hline $2,3,4,7,9,11,16,17$ & $\begin{array}{l}\text { Inability } \\
\text { understand } \\
\text { numbers } \\
\end{array}$ & $\begin{array}{l}\text { Linguistic process } \\
\text { Connecting process }\end{array}$ & $\begin{array}{l}\text { Word by Word meaning } \\
\text { Context clues } \\
\text { Selecting to move on }\end{array}$ \\
\hline
\end{tabular}

Intermediate learners experienced the same aural problems, activated the same processes but their selection of strategies was different. Besides, other strategies were added. The strategy "word by word meaning" was used to solve all problems. It indicated that intermediate learners prefer to use bottom up strategies in listening. "Selecting to move on" came in the second place of use by the intermediate learners. "Background Knowledge, "Context clues and Associating" were used to solve only two problems.

Table 3. The Percentage of Occurrence of the Listening Problems in the Advanced and Intermediate Groups

\begin{tabular}{lll}
\hline Problem Type & Advanced & Intermediate \\
\hline Hearing unknown words & $60 \%$ & $75 \%$ \\
\hline Hearing words incorrectly & $15 \%$ & $35 \%$ \\
\hline Words with multiple meanings & $40 \%$ & $60 \%$ \\
\hline Known words with no connection to the topic & $35 \%$ & $65 \%$ \\
\hline Inability to recognize proper names & $25 \%$ & $50 \%$ \\
\hline Inability to understand numbers & $20 \%$ & $40 \%$ \\
\hline
\end{tabular}

Table 3 shows that the most frequent problem encountered by both groups is "hearing unknown words". It has also been found that both groups encountered the same listening problems with different percentage of occurrence. In the intermediate group, the percentage of occurrence was almost double the percentage in the advanced group.

Table 4. The Percentage of Listening Strategies Used by Advanced and Intermediate Participants

\begin{tabular}{lll}
\hline Strategy & Advanced & Intermediate \\
\hline Background knowledge & $70 \%$ & $30 \%$ \\
\hline Context clues & $45 \%$ & $30 \%$ \\
\hline Associating & $40 \%$ & $30 \%$ \\
\hline Making inferences & $25 \%$ & $10 \%$ \\
\hline $\begin{array}{l}\text { Seeking confirmation, } \\
\text { Rejecting wrong hypotheses }\end{array}$ & $25 \%$ & $20 \%$ \\
\hline Recognizing stress & $35 \%$ & $25 \%$ \\
\hline Recalling similar sounds & $35 \%$ & $25 \%$ \\
\hline Word by Word meaning & $10 \%$ & $75 \%$ \\
\hline Vocalization/Visualization & $30 \%$ & $30 \%$ \\
\hline Making prediction & $15 \%$ & $5 \%$ \\
\hline Selecting to move on & $10 \%$ & $50 \%$ \\
\hline
\end{tabular}

Table 4 shows that the most frequent strategy selected and used by advanced participants was "Background Knowledge" whereas "word by word meaning" was the most frequent strategy used by intermediate participants. 
It was also found that the advanced group used top down strategies more than the intermediate group such as the strategies "Background Knowledge", "Making Inferences" and "Associating". The intermediate group used bottom up strategies more than the advanced group such as "Word by Word meaning".

\section{Conclusion}

The current study was an attempt to discover the mental steps which the learners go through while listening to English as a foreign language. It tried to shed light on the kinds of problems which advanced and intermediate learners encounter, the planning processes which they activate, and the strategies selected to solve the listening problems. The researcher used the "think aloud" method to collect data from the participants.

Regarding "think aloud" as a method of data collection, it must be remembered that it is reliable for what it contains. The controlled processes are experienced when a problem is encountered; therefore, "think aloud" can be used to capture most of the steps involved in the solution of a perceived problem. The current study looked specifically at the controlled processes involved in listening comprehension rather than at automated processes.

The researcher adopted Faerch and Kasper's (1980) model of intellectual behavior in order to identify the problem solving processes activated. The analysis of verbal data according to the theoretical model offered by Faerch and Kasper produced interconnecting taxonomies of six problems, three planning processes, and eleven strategies. It has been found that this study assured the findings of previous studies. It emphasized that analyzing listening comprehension strategies and training learners to use them are essential for developing learners' listening skill.

\section{Recommendations}

Based on the findings of this study, the following recommendations are presented:

1. Teachers should help students recognize their learning strategies, strengthen them, and generate new ones. Learners need to participate in activities that help them examine what the listening process entails and they need to explore this process by themselves. Once their exploration of the process has been initiated, they need to be guided in the use of alternative strategies for listening.

2. Teachers should encourage their students to talk about their listening problems and the strategy used to solve them. This includes discussing when, how, and why they choose certain strategies. In these strategy discussions, teachers can lead students to realize what listening strategies they could use as they listen by providing practical examples and real listening situations.

3. Students should also be taught how to use immediate-retrospective techniques. As students produce immediate retrospective reports, the teacher has the opportunity to diagnose listening difficulties and identify specific listening strategies.

4. It is also recommended that teachers should help students compare and contrast the various problem-solving strategies in different situations.

\section{Acknowledgment}

I would like to thank my professor Dr. Ahmed H. Seifeddin for his help and guidance. I would also like to thank my colleagues who helped me to conduct the experiment. My special thanks are extended to my family who supported me throughout the study.

\section{References}

Amin, I. A., Amin, M. M., \& Aly, M. A. (2011). A Correlation Study between EFL Strategic Listening and Listening Comprehension Skills among Secondary School Students. On line Submission. ED527448.

Attia, A. E. (2002). The effect of a strategy-based instruction programme on developing EFL listening comprehension skills. PhD thesis, University of Warwick.

Carissa, M. Y. (1997). A Serial Ordering of Listening Comprehension Strategies Used by Advanced ESL Learners in Hong Kong. ELT Journal, 7, 35-53.

Chamot, A. U. (2005). The Cognitive Academic Language Learning Approach (CALLA): An update. In P. A. Richard-Amato, \& M. A. Snow (Eds.), Academic success for English language learners: Strategies for K-12 mainstream teachers (pp. 87-101). White Plains, NY: Longman.

Corder, S. (1982). Communication Strategies. Error Analysis and Interlanguage. New York: Oxford University Press. 
DeFilippis, A. (1980). A Study of the Listening Strategies Used by Skillful and Unskillful College French Students in Aural Comprehension Tasks. Unpublished PHD Dissertation: University of Pittsburgh.

Doff, A., \& Christopher J. (2004). Language in Use: Upper Intermediate Classroom Book. New Delhi: Foundations Books Pvt, Ltd.

Ellis, R. (1986). Understanding Second Language Acquisition. Oxford University Press.

Ericsson, A., \& Simon, A. (1984). Protocol Analysis Verbal Reports as Data. Cambridge. Mass: MIT Press.

Ericsson, A., \& Simon, A. (1987). Verbal reports on thinking. In Faerch, \& Kasper (eds.), Introspection in Second Language Research (pp. 24-53). Clevedon, Philadelphia:Multilingual Matters Ltd.

Faerch, C., \& Kasper, G. (1980). Processes and strategies in foreign language learning and communication. Interlanguage Studies Bulletin, 5(1), 47-118.

Faerch, C., \& Kasper, G. (eds.). (1983). Strategies in Interlanguage Communication. London: Longman Group Ltd.

Faerch, C. (1984). Strategies in production and reception: some empirical evidence. In Davies, A., Criper, C., \& Howatt, R. (eds.), Interlanguage (pp. 49-705). Edinburgh: Edinburgh University Press.

Faerch, C., \& Kasper, G. (1984). Two ways of defining communication strategies. Language Learning, 34(1), 45-62.

Faerch, C., \& Kasper, G. (eds.). (1987). Introspection in Second Language Research. Clevedon, Philadelphia: Multilingual Matters Ltd.

Freeman, D. L. (2004). Techniques and Principles in Language Teaching. New Delhi: OUP.

Goh, C. C. M. (2000). A cognitive perspective on language learners' listening comprehension problems. System, 28, 55-75. http://dx.doi.org/10.1016/s0346-251x(99)00060-3

Kasper, G. (1984). Pragmatic comprehension in learner-native speaker discourse. Language Learning, 34(4), pp. $1-20$.

Lin, M. (2006). The effects of note-taking, memory and rate of presentation on EFL learners' listening comprehension. Unpublished doctoral dissertation, La Sierra University, California.

Long, M. H., \& Ross, S. J. (2009). Input elaboration: a viable alternative to "authentic" and simplified texts. In K. Nakai (Ed.), Festschrift for Yasutaka Yano (pp. 307-323). Tokyo: Waseda University Press.

Martin, T. (1982). Introspection and the Listening Process. Master thesis. University of California. Los Angeles.

Nekrasova, T. M. (2009). English L1 and L2 speakers' knowledge of lexical bundles. Language Learning, 59(3), 647-686. http://dx.doi.org/10.1111/j.1467-9922.2009.00520

Osada, N. (2004). Listening comprehension research: A brief review of the past thirty years. Dialogue, 3, 53-66.

Piolat, A. (2008). Fluency and Cognitive Effort During First- and Second-Language Notetaking and Writing by Undergraduate Students. European Psychologist. 13(2), ISSN1016-9040. http://dx.doi.org/10.1027/1016-9040.13.2.114

Rivers, W. (1981). Teaching Foreign Language Skills. University of Chicago Press.

Sadighi, F., \& Zare, S. (2006). Is listening comprehension influenced by the background knowledge of the learners? A case study of Iranian EFL learners. The Linguistics Journal, 1(3), 110-126.

Sakai, H. (2009). Effect of repetition of exposure and proficiency level in L2 listening tests. TESOL Quarterly, 43(2), 360-371.

Sharma, D. (2006). The Art of Communication. The Journal of English Language Teaching (India), XLIV/5, 41-43.

Sharma, D. (2007). Teaching English as a Second Language. New Delhi: Deep and Deep Pvt. Ltd.

Song, M. Y. (2008). Do divisible subskills exist in second language (L2) comprehension? A structural equation modeling approach. Language Testing, 25(4), 435, 464.

Taguchi, N. (2005). Comprehending implied meaning as a foreign language. The Modern Language Journal, 89, 543-562. http://dx.doi.org/10.1111/j.1540-4781.2005.00329.x

Underwood, M. (1989). Teaching listening. New York: Longman. 
Vandergrift, L. (2007). Recent developments in second and foreign language listening comprehension research. Language Teaching, 40(3), 191-210. http://dx.doi.org/10.1017/s02614448807004338

Vandergrift, L., \& Tafaghodtari, M. H. (2010). Teaching L2 learners how to listen does make a difference: An empirical study. Language Learning. http://dx.doi.org/10.1111/j.1467-9922.2009.00559

\section{Appendix 1.}

\section{A Listening Comprehension Test}

\section{Instructions:}

The test consists of two passages. After listening to each passage, answer the questions according your comprehension of what you have listened to.

First, you are going to listen to a passage about Christopher Columbus. Listen carefully and then answer the following questions.

1.) Where was Christopher Columbus born?
A. The New World
B. Portugal
C. Spain
D. Italy

2.) King Ferdinand and Queen Isabella agreed to pay for his trip in
A.1941
B. 1944
C. 1942
D. 1943
3.) Columbus' discoveries set the stage for the Age of
A. Exploration
B. Globalization
C. Technology
D. Speed
4.) After----- at sea, land was finally sighted
A. one month
B. two months
C. three months
D. four months

5.) Which is not True?

A. Columbus was born in Italy

B. Columbus received three ships and a crew from the

King and Queen of Spain

C. Columbus found a shortcut to the Indies

D. The journey across the Atlantic took two months

6.) Columbus named the native people he saw
A. Africans
B. Europeans
C. Indians
D. Americans

7.) Which of the following was NOT one of his ships?
A. Nina
B. Pinta
C. Isabella
D. Santa Maria

8.) Why was Christopher Columbus very important?

A. He believed he found a shortcut to the Indies

B. He first used the word "Indians"

C. He discovered a whole new continent

D. He was one of the bravest explorers of all time 
Second, you are going to listen to a passage about Butterflies. Listen carefully and then answer the following questions

1.) A butterfly goes through----- stages of life
A. Three
B. Four
C. Five
D. six

2.) Which of the following is NOT true?

A. Butterflies must wait until blood drains into their wings before flying.

B. The butterfly may shed its skin 8 or 9 times

C. Caterpillars turn into a liquid in the chrysalis

D. Most butterflies live a short time

3.) In what stage does the metamorphosis happen?
A. Butterfly
B. Caterpillar
C. Chrysalis
D. Egg

4.) There are about-------- different kinds of butterflies in the world.
A. a thousand
B. more than a thousand
C. less than a thousand
D. only two

5.) What is the reason for shedding its skin?
A. to eat
B. to move
C. to grow
D. To defend itself against predators

6.) What is the form of a butterfly in the second stage of life?
A. Larva
B. Chrysalis
C. Butterfly
D. Egg

7.) What is the third stage of life for a butterfly?
A. Larva
B. Chrysalis
C. Butterfly
D. Egg

8.) Specify what a butterfly does.
A. goes through metamorphosis
B. lays eggs
C. mates
D. drinks nectar from flowers 